\title{
Morfogênese de gramíneas nativas do Rio Grande do Sul (Brasil) submetidas a pastoreio rotativo durante primavera e verão
}

\author{
Rio Grande do Sul State's (Brazil) native grasses morphogenesis under \\ rotational grazing during spring and summer
}

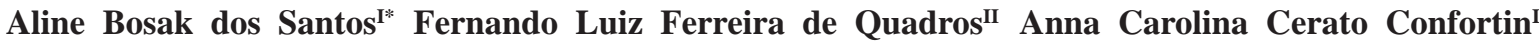
Liane Seibert ${ }^{\mathrm{II}}$ Bruna San Martim Rolim Ribeiro ${ }^{\mathrm{II}}$ Paula de Oliveira Severo ${ }^{\mathrm{II}}$ Pedro Trindade Casanova ${ }^{\text {II }}$ Greice Kelly Gomes Machado ${ }^{\text {II }}$
\end{abstract}

RESUMO

O trabalho objetivou determinar a influência de intervalos de pastoreio rotativo sobre a morfogênese de cinco gramíneas nativas da região central do Rio Grande do Sul (RS), agrupadas segundo uma tipologia funcional, nas estações de primavera e verão. Foram avaliadas taxa de aparecimento, elongação e senescência foliares (TAF/TEF/TSF), filocrono e duração de vida e de elongação foliares (DVF/DEF) em Axonopus affinis, Aristida laevis, Andropogon lateralis, Paspalum notatum e Paspalum plicatulum, sob dois intervalos de pastoreio rotativo, definidos por somas térmicas $\left({ }^{\circ} \mathrm{C}\right), 375$ e 750 graus-dia, na primavera 2010 e verão 2010/2011. Não houve diferença significativa entre intervalos de pastoreio, mas houve entre espécies e entre estações. Paspalum notatum se destacou por apresentar adaptações bem marcadas ao pastejo. Axonopus affinis $e$ P. notatum foram as espécies com maiores TAF e menores DVF, já A. lateralis apresentou características morfogênicas que contradizem a literatura. Quanto às estações, primavera se caracterizou como a estação de crescimento, e verão, como o início do florescimento. Pastejo afeta a morfogênese de forrageiras, no entanto, os intervalos de pastoreio usados não têm efeito sobre o desenvolvimento das espécies e a influência estacional é marcante no desenvolvimento dessas gramíneas.

Palavras-chave: duração da expansão foliar, manejo, morfogênese, pastejo.

\section{ABSTRACT}

The influence of rotational grazing intervals on morphogenesis of five native grasses from Rio Grande do Sul state (RS) central region, grouped according to a functional typology, was evaluated during spring and summer seasons. Leaf appearance rate, leaf elongation rate and leaf senescence rate ( $L A R / L E R / L S R)$ phyllochron, leaf lifespan and leaf elongation duration (LLP/LED) were evaluated on Axonopus affinis, Aristida laevis, Andropogon Iateralis, Paspalum notatum and Paspalum plicatulum, under two rotational grazing intervals, defined by thermal time $\left({ }^{\circ} \mathrm{C}\right), 375$ and 750 degree-day, during 2010 spring and 2010/2011 summer. There was no significant difference between grazing intervals, but there was among species and between seasons. Paspalum notatum highlights significant adjustments to grazing. Axonopus affinis and $\boldsymbol{P}$. notatum presented the largest $L A R$ and smallest $L L P$, while $A$. lateralis presented morphogenic characteristics which contradict literature. Spring and summer was characterized as the growing and flowering periods, respectively. Grazing showed influence on forage morphogenesis, however, the evaluated grazing intervals had no effect on species development and the seasonal influence define native grasses development.

Key words: grazing, leaf elongation duration, management, morphogenesis.

\section{INTRODUÇÃO}

Evidências indicam que a dinâmica de evolução dos campos naturais sul-americanos, incluindo o bioma Pampa, está associada a um regime de distúrbios naturais como herbivoria e queimadas (BEHLING \& PILLAR, 2007), determinando uma forte influência nas espécies. O pastejo é o fator mais importante que afeta a vegetação herbácea na maioria das áreas de pastagem natural do mundo. No entanto, respostas de comunidades vegetais ao pastejo são de difícil predição, devido ao número de espécies nas pastagens naturais (CRUZ et al., 2010).

Assim, o estudo de espécies baseado em uma tipologia funcional surge como ferramenta auxiliar no reconhecimento e manejo de ambientes de alta diversidade. A classificação em tipos funcionais

IInstituto Federal de Educação, Ciência e Tecnologia Farroupilha, Câmpus Alegrete, RS 377, Km 27, Passo Novo, 97555-000, Alegrete, RS, Brasil. E-mail: alinebosaksantos@gmail.com.*Autor para correspondência.

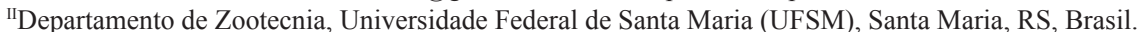

Recebido 10.05.12 Aprovado 12.04.13 Devolvido pelo autor 31.11.13 CR-2012-0216.R1 
consiste no agrupamento de espécies segundo respostas comuns ao ambiente ou processos do ecossistema (CRUZ et al., 2010). Os tipos funcionais (TF) utilizados consistem de conjuntos de gramíneas com características semelhantes, quanto ao teor de matéria seca (TMS, g $\mathrm{kg}^{-1}$ ) e área foliar específica (AFE, $\mathrm{m}^{2} \mathrm{~kg}^{-1}$ ) das lâminas foliares (QUADROS et al., 2009).

Para melhor entendimento dos processos fisiológicos do desenvolvimento vegetal, o estudo de características morfogênicas se baseia no aparecimento, elongação e duração de vida das folhas, em pastagens em estado vegetativo. No entanto, para espécies nativas do Rio Grande do Sul (RS), trabalhos avaliando a morfogênese dessas plantas, sob critérios de manejo baseados em uma característica morfogênica, ainda são escassos.

Este trabalho objetivou avaliar a morfogênese de gramíneas nativas na região central do RS, submetidas a dois intervalos de pastoreio rotativo, determinados por somas térmicas, durante as estações de primavera e verão.

\section{MATERIAL E MÉTODOS}

O trabalho foi desenvolvido em área pertencente à Universidade Federal de Santa Maria, localizada na região fisiográfica da Depressão Central/RS, coordenadas $29^{\circ} 43^{\prime} \mathrm{S}, 53^{\circ} 42^{\prime} \mathrm{W}$, com altitude de $95 \mathrm{~m}$ acima do nível do mar. O clima da região é $\mathrm{Cfa}$, subtropical úmido, segundo a classificação de Köppen. As variáveis meteorológicas do período de avaliação assim como médias históricas se comportaram da seguinte forma: temperatura média na primavera (real $20,6^{\circ} \mathrm{C}$; histórica $21^{\circ} \mathrm{C}$ ), no verão (real $24^{\circ} \mathrm{C}$; histórica $23,6^{\circ} \mathrm{C}$ ); precipitação pluviométrica média na primavera (real $80 \mathrm{~mm}$; histórica $137 \mathrm{~mm}$ ), no verão (real $160 \mathrm{~mm}$; histórica $142 \mathrm{~mm}$ ) (Estação Meteorológica do 8o Distrito de Meteorologia, localizado na UFSM/rede do Instituto Nacional de Meteorologia - INMET).

As avaliações ocorreram no período de setembro de 2010 a março de 2011. O estudo foi realizado em delineamento experimental inteiramente casualizado com dois tratamentos e três repetições, sorteadas em uma área de 24 hectares (ha), subdividida em potreiros de 0,5ha. Foram avaliados dois intervalos de pastoreio rotativo (375 e 750 graus-dia (GD)) e o critério utilizado para determinar o intervalo de pastoreio foram somas térmicas acumuladas, equivalentes à duração média da expansão foliar das espécies representativas dos grupos funcionais A (375GD) e D (750GD), respectivamente (QUADROS et al., 2009).
Avaliaram-se então áreas pastoreadas com intervalo de pastoreio curto, de 375 GD (IC), e áreas pastoreadas com intervalo de pastoreio longo, de 750GD (IL), sendo a soma térmica obtida através da equação: $\mathrm{ST}=\Sigma$ Tmd, em que $\Sigma$ Tmd é o somatório das temperaturas médias diárias do período (INMET, 2004). Nos piquetes do IL, predominava inicialmente o estrato superior formado por espécies cespitosas e essa característica se manteve parcialmente após o manejo adotado. Nos piquetes do IC, a altura do dossel de plantas era menor, com predominância do estrato inferior, a qual se intensificou ao longo da adoção do manejo avaliado.

Foram sorteadas para avaliação seis parcelas experimentais de 0,5ha, sendo três representativas do IC e três do IL. As parcelas representativas apresentavam em sua composição todas as espécies abaixo citadas, em proporções diferentes, segundo os intervalos avaliados. As espécies avaliadas são enquadradas nos tipos funcionais (TF) A, B, C e D, segundo o TMS ( $\mathrm{g}$ $\left.\mathrm{kg}^{-1}\right)$ e a AFE $\left(\mathrm{m}^{2} \mathrm{~kg}^{-1}\right)$ (QUADROS et al., 2009): Axonopus affinis Chase (TF A), Andropogon Iateralis Nees e Paspalum notatum Füegge (TF B), Paspalum plicatulum Michx. (TF C) e Aristida laevis Nees (TF D). Gramíneas dentro do TF A apresentam valores das variáveis consideradas entre $<300$ TMS e >20AFE; no TF B, 300 a 400TMS e 14 a 16AFE; no TF C, 400 a 500TMS e 8 a $12 \mathrm{AFE}$ e no TF D, >500TMS e <8AFE. A escolha das espécies se deu pela abundância na massa de forragem nas pastagens naturais da região da Depressão Central do RS e por serem espécies representantes dos TF supracitados.

A ocupação da pastagem correspondeu ao tempo necessário para a redução a um valor de massa de forragem (MF) residual entre 1500 a $2000 \mathrm{~kg} \mathrm{ha}^{-1}$ de MS (dois a quatro dias). Os animais experimentais foram novilhas (dois animais por potreiro), com idade inicial de 17 meses e bezerras (também dois animais por potreiro), com sete meses, como animais-teste (total de quatro animais-teste por potreiro avaliado) e mais animais reguladores da MF. O número de animais reguladores era definido em função da diferença entre a MF inicial e a residual acima citada, considerando um desaparecimento diário de forragem equivalente a $4,5 \%$ do peso vivo, e variou de 10 a 15 animais.

Para a determinação das variáveis morfogênicas, foi utilizada a técnica de "perfilhos marcados", descrita por CARRÈRE et al. (1997). Em cada potreiro, foram marcados, com fios telefônicos coloridos de $1,0 \mathrm{~mm}$ de espessura, vinte perfilhos vegetativos por espécie, escolhidos aleatoriamente ao 
longo do potreiro em um transecto de cerca de $50 \mathrm{~m}$, a fim de que este fosse representativo da área.

As avaliações foram realizadas a cada sete dias, quando foram contadas as folhas verdes e medido o comprimento da lâmina foliar $(\mathrm{cm})$. As folhas completamente expandidas foram medidas a partir de sua lígula; as folhas em expansão foram medidas a partir da lígula da última folha completamente expandida e, nas folhas em senescência, foi medida apenas a porção verde da lâmina foliar. A partir dos dados obtidos, foram calculadas as variáveis taxa de aparecimento foliar (TAF; folhas/GD), filocrono (GD), duração de vida foliar (DVF; GD), duração de elongação foliar (DEF; GD), taxa de senescência foliar (TSF; cm/GD) e taxa de elongação foliar (TEF; $\mathrm{cm} / \mathrm{GD}$ ), para as estações de primavera e verão.

O aparecimento foliar foi calculado a partir do coeficiente angular da regressão linear entre o número de folhas surgidas por perfilho e a soma térmica acumulada. O filocrono foi considerado como o valor inverso da TAF. A DEF foi obtida a partir do produto entre o número médio de folhas em expansão e o filocrono correspondente, e a DVF, pelo produto do número médio de folhas verdes por perfilho e seu filocrono. A elongação de folha foi calculada a partir da relação entre a variação do comprimento das folhas em elongação entre duas avaliações sucessivas e a soma térmica acumulada no período correspondente. A senescência foliar, a partir da relação entre a variação do comprimento do material senescente foliar entre duas avaliações e a soma térmica acumulada no período correspondente. Os dados das características morfogênicas foram submetidos à análise de ordenação, através da análise de coordenadas principais, com a padronização dos dados pela amplitude de variação, e a análise de variância, utilizando testes de aleatorização com o software MULTIV (PILLAR, 2004), comparando os intervalos de pastoreio, as estações e as espécies.

\section{RESULTADOS E DISCUSSÃO}

A figura 1 representa a relação entre as variáveis morfogênicas das espécies avaliadas ao longo das estações de primavera e verão. O diagrama de ordenação sintetizou $85,3 \%$ da variação presente entre as variáveis morfogênicas das espécies e as estações. O lado esquerdo do diagrama foi caracterizado pela TAF e pelas espécies $\boldsymbol{P}$. notatum e A. affinis, nas duas estações, assim, como por $\boldsymbol{A}$. lateralis, no verão, ou seja, as espécies supracitadas apresentaram maiores valores dessa variável. Este resultado era esperado, uma vez que as espécies são representantes de TF (A e B) que enquadram espécies com alta renovação foliar, caracterizadas por altas TAF, e reduzidos filocrono e duração de vida foliar. A última espécie exibe plasticidade fenotípica para essas características (QUADROS et al., 2009).

AFigura 1 ressalta também a relação inversa existente entre as variáveis, aparecimento foliar e taxa de elongação foliar, sob as condições experimentais utilizadas. Sendo assim, o seu afastamento no plano do diagrama indica a relação inversa entre essas. Nos quadrantes direito, inferior e superior, concentram-se as demais variáveis morfogênicas avaliadas.

É importante destacar a relação das espécies P. plicatulum e A. laevis com as variáveis, duração de elongação foliar, TEF e senescência foliar, nas duas estações. Conforme apresentado na tabela 1, são as espécies que apresentaram maiores valores para as duas últimas variáveis, pois essas são espécies de hábito de crescimento cespitoso, que formam touceiras densas, de maior tamanho final de folha, e A. laevis principalmente, com grande acúmulo de matéria morta (QUADROS et al., 2009).

Como não houve diferença significativa entre os intervalos de pastoreio, mas houve entre espécies $(\mathrm{P}<0,001)$ e entre estações $(\mathrm{P}<0,001)$, os dados das variáveis morfogênicas avaliadas são apresentados em valores médios por espécie em cada estação na tabela 1. Foi observada, em média, redução nas TAF para as cinco espécies avaliadas e consequentemente aumento dos filocronos da primavera para o verão. O filocrono corresponde ao valor inverso da TAF, e essa característica desempenha papel central na estrutura do pasto, pois é relacionada com as características estruturais da pastagem.

As espécies que apresentaram as maiores TAF foram A. affinis e $\boldsymbol{P}$. notatum nas duas estações (Tabela 1). Essas espécies são enquadradas nos TF A e B que se caracterizam por apresentar altas TAF e reduzidos intervalos de aparecimento de folhas, representando alta renovação foliar. Essas características permitem às plantas serem submetidas a eventos de desfolhas frequentes e sob alta carga animal. Altas TAF podem reduzir a probabilidade de desfolhação, assim pode ser vista como um mecanismo de escape ao pastejo (BRISKE, 1991).

MACHADO (2010), estudando oito espécies nativas do RS sob adubação nitrogenada de $100 \mathrm{~kg} \mathrm{ha}^{-1}$ de N no verão, obteve para $\boldsymbol{A}$. affinis e $\boldsymbol{P}$. notatum, TAF média de 0,007 folhas/GD, não encontrando diferença estatística entre os tratamentos. Fatores como limitações hídricas e nutricionais podem influenciar essas variáveis, assim como aspectos relacionados às variações na altura e oferta 


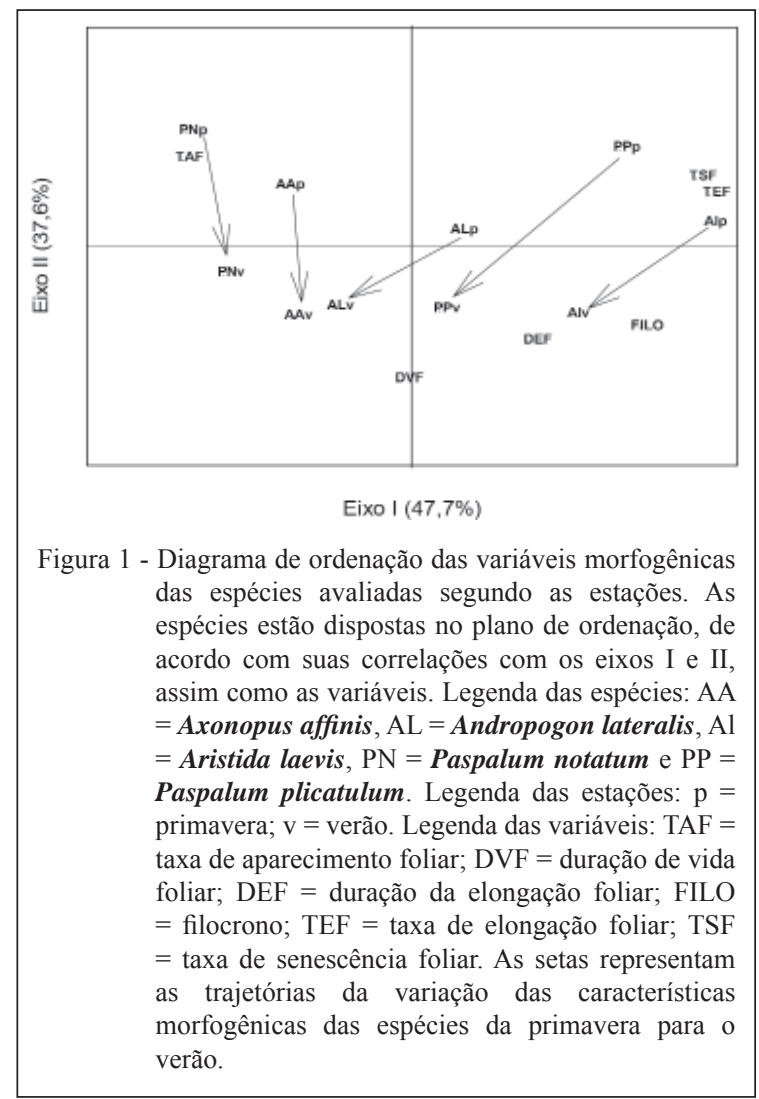

de forragem. Entretanto, as médias pluviométricas do período experimental foram semelhantes às médias históricas de Santa Maria/RS, nos meses de avaliação, não influenciando possivelmente nos resultados.

TRINDADE \& ROCHA (2002), buscando avaliar a resposta morfogênica aos distúrbios fogo e pastejo de A. lateralis, gramínea muito abundante nas pastagens naturais de várias regiões do bioma Pampa, obtiveram filocrono médio de 495GD, sendo o menor valor dessa variável obtido no tratamento pastejado e sem queima (325GD), aproximando-se mais dos valores encontrados neste trabalho. Apesar das alternativas de manejo diferentes, a espécie expressou seu potencial de crescimento. Autores como TRINDADE \& ROCHA (2001) afirmam que A. Iateralis é uma espécie de crescimento lento, entretanto, segundo os resultados obtidos neste estudo, a espécie apresenta valores intermediários de TAF/ filocrono, se comparado às outras espécies avaliadas, as quais são mais bem conhecidas por desenvolvimento satisfatório, visando à produção animal.

Acredita-se que o efeito mais importante sobre a vegetação natural é o do pastejo, pois a remoção da área foliar ao longo de toda a estação de crescimento afeta sua taxa de acumulação, sendo essa diretamente influenciada pelos ritmos de surgimento e alongamento dos tecidos foliares, principalmente. Além disso, a reação da planta à desfolhação envolve características adaptativas fisiológicas e morfológicas, tais como a restrição de carboidratos durante $o$ crescimento da planta e a plasticidade fenotípica, a qual confere tolerância da planta ao pastejo (BRISKE, 1991). É possível notar redução dos valores de TAF e elongação foliar da primavera para o verão (Tabela 1). VILELA et al. (2005), estudando as características morfogênicas e estruturais de Cynodon dactylum cv. Coastcross, gramínea cultivada de estação quente, manejada sob lotação rotacionada com vacas em lactação, registraram maior aparecimento foliar na primavera e maior TEF no verão. No presente trabalho, essa variação estacional da morfogênese vegetal foi observada de forma semelhante para TAF, mas diferente para TEF nas espécies nativas avaliadas.

SANTOS (2005), avaliando a dinâmica de crescimento de quatro gramíneas nativas do gênero Paspalum, através de características morfogênicas, obteve para $\boldsymbol{P}$. notatum, filocrono médio entre dois ecótipos avaliados de 156GD, na primavera, e 220GD, no verão. Neste estudo, foram encontrados valores inferiores aos de SANTOS (2005), o que permite inferir sobre o efeito modificador do pastejo na morfogênese das plantas, mesmo não tendo ocorrido diferença significativa entre os intervalos de pastoreio avaliados.

A duração de vida da folha, tempo decorrido entre o surgimento de uma folha e o início de sua senescência é uma característica morfogênica de grande importância e que pode ser usada no manejo de pastagens. Plantas com altas TAF apresentam folhas menos longevas (QUADROS et al., 2009), pois, com a alta renovação de tecidos foliares, esses são usados na ciclagem de nutrientes, através da sua mobilização das folhas velhas para formação das novas. Paspalum notatum, assim com A. affinis, apresentou valores altos de DVF, se comparado aos resultados de MACHADO (2010) para a mesma espécie. A autora obteve DVF para a espécie de 704GD, no verão, sob adubação nitrogenada. Porém, trabalhos com espécies tropicais cultivadas mostram tanto diminuição como aumento da DVF com uso de N.

SANTOS (2005) obteve para $\boldsymbol{P}$. notatum, DVF de 1543GD no ecótipo "André da Rocha" no verão, valor este semelhante ao encontrado no presente trabalho. No entanto, tanto em MACHADO (2010) quanto em SANTOS (2005), o uso de adubação nitrogenada influenciou nos resultados. Aumentos na TAF por efeito do $\mathrm{N}$ atuam de forma oposta junto à 
Tabela 1 - Valores médios dos dois intervalos de pastoreio para taxa de aparecimento (TAF; $\mathrm{n}^{-}$folhas graus ${ }^{-1}$-dia), filocrono (FILO; grausdia), duração de vida foliar (DVF; graus-dia), duração de elongação foliar (DEF; graus-dia), taxa de elongação foliar (TEF; cm graus $^{-1}$-dia) e taxa de senescência foliar (TSF; cm graus ${ }^{-1}$-dia) na primavera e verão. Santa Maria/RS.

\begin{tabular}{|c|c|c|c|c|c|}
\hline Espécie & A. affinis & A. laevis & A. lateralis & P. notatum & P. plicatulum \\
\hline TAF & $0,0041(24,3)^{*}$ & $0,0026(19,9)$ & $0,0032(24)$ & $0,007(18,8)$ & $0,0035(20,2)$ \\
\hline FILO & $266(22,8)$ & $399(18,4)$ & $395(22,8)$ & $151(18,2)$ & $294(19,2)$ \\
\hline DVF & $1142(22,6)$ & $1310(25,5)$ & $1188(25,5)$ & $1012(18,5)$ & $1075(22,9)$ \\
\hline DEF & $350(22,7)$ & $525(17,2)$ & $436(22,7)$ & $400(28,1)$ & $409(20,5)$ \\
\hline TEF & $0,021(41,3)$ & $0,064(45,4)$ & $0,032(52,7)$ & $0,024(36,1)$ & $0,052(44,4)$ \\
\hline TSF & $0,033(81)$ & $0,117(93,7)$ & $0,057(89,3)$ & $0,033(72)$ & $0,138(66)$ \\
\hline Espécie & A. affinis & A. laevis & $\begin{array}{l}\text { A. lateralis } \\
\text { DERAO--- }\end{array}$ & P. notatum & P. plicatulum \\
\hline TAF & $0,0034(24,7)$ & $0,0023(24,4)$ & $0,0031(27,6)$ & $0,0051(27,4)$ & $0,0033(27,4)$ \\
\hline FILO & $338(21,3)$ & $470(23,4)$ & $355(28,9)$ & $210(25,5)$ & $325(22,6)$ \\
\hline DVF & $1538(22,3)$ & $1325(28,6)$ & $1473(28,3)$ & $1427(29,4)$ & $1603(27,3)$ \\
\hline DEF & $434(22,2)$ & $604(25,9)$ & $486(26,1)$ & $553(27)$ & $503(24,5)$ \\
\hline TEF & $0,012(45,3)$ & $0,039(51,1)$ & $0,016(38,6)$ & $0,014(48,8)$ & $0,032(42,9)$ \\
\hline TSF & $0,012(47,3)$ & $0,052(61,7)$ & $0,021(59,6)$ & $0,015(63,5)$ & $0,041(43,4)$ \\
\hline
\end{tabular}

* Coeficientes de variação (\%).

DVF, reduzindo-a. Os elevados valores de DVF para P. notatum demonstraram que, sob pastoreio rotativo, as folhas dessa espécie são mais duradouras do que sob outras condições, como adubação nitrogenada, conforme discutido anteriormente.

As maiores DVF foram observadas, em média, nas espécies A. laevis e $\boldsymbol{P}$. plicatulum, assim como as maiores DEF e TEF. Sendo as espécies $\boldsymbol{A}$. laevis e $\boldsymbol{P}$. plicatulum pertencentes aos TF D e C (QUADROS et al., 2009), respectivamente, os valores mais elevados de DVF podem ser associados às suas características de plantas conservadoras de recursos. O agrupamento em TF aborda também características específicas como elongação foliar; o TF D (A. laevis), por exemplo, agrupa espécies com alta elongação foliar, ou seja, altas TEF e DEF.

A DEF, tempo em que as folhas permanecem alongando, é diretamente relacionada à TEF e ao comprimento final da lâmina foliar. Os menores valores de DEF foram obtidos para $\boldsymbol{A}$. affinis. O TF A (A. affinis,) agrupa espécies com alta renovação foliar, ou seja, espécies com alta TAF e consequentemente reduzidas TEF e duração da elongação de folha. As maiores TEF foram observadas nas espécies A. laevis e P. plicatulum (Tabela 1). Paspalum plicatulum obteve a maior TEF $(0,0084 \mathrm{~cm}$ $\mathrm{GD}^{-1}$ ), na primavera no IL. MACHADO (2010) encontrou, para $\boldsymbol{P}$. notatum, TEF de $0,0146 \mathrm{~cm} \mathrm{GD}^{-1}$, no verão. BANDINELLI et al. (2003), avaliando A. lateralis sob quatro níveis de $\mathrm{N}$, obtiveram valores médios de TEF de 0,505 e $0,58 \mathrm{~mm} \mathrm{GD}^{-1}$, na primavera e verão, respectivamente, valores superiores aos deste trabalho. Neste estudo, foram encontrados, para A. lateralis, valores de TEF aproximados aos de MACHADO (2010), reforçando o conhecimento da plasticidade fenotípica da espécie, a qual permite sua adaptação a diferentes ambientes e manejos, através de alterações em sua estrutura.

Aumentos na DEF podem ser relacionados a aumentos no pseudocolmo, marcando assim o início do período reprodutivo, seguido pelo alongamento dos entrenós. Do mesmo modo, os maiores valores de filocrono encontrados no verão para as espécies citadas estão relacionados a isso. Segundo QUADROS et al. (2005), ocorre uma alteração de prioridade na alocação das reservas, que deixam de ser destinadas às folhas, promovendo redução na elongação foliar, para serem gastas no alongamento dos entrenós do colmo.

Em relação às taxas de senescência encontradas, os maiores valores foram observados nas espécies A. laevis e $\boldsymbol{P}$. plicatulum. A senescência foliar é um processo que implica perda da atividade metabólica e pode ser influenciada pelo ambiente, estádio de desenvolvimento e características das espécies. A maior senescência foliar observada na primavera pode ser resultado ainda da alta produção de biomassa no período, estação de crescimento, e de possível uso de carga animal inferior ao potencial produtivo da pastagem. Conforme a tabela 1, nota-se que as taxas de senescência foram sempre superiores às TEF. Por isso, é possível que o manejo adotado não tenha sido eficiente na colheita da matéria verde 
produzida, ou seja, a carga animal. Isso significa dizer que, o protocolo estabelecido não permitiu realizar a completa desfolha das folhas individuais antes que estas alcançassem o tempo de vida e iniciassem o processo de senescência.

As TSF encontradas no trabalho são semelhantes (Tabela 1) às encontradas por MACHADO (2010), de $0,025 \mathrm{~cm} \mathrm{GD}^{-1}$, e por BANDINELLI et al. (2003), de $0,215 \mathrm{~mm} \mathrm{GD}^{-1}$, para A. lateralis, no verão. As menores taxas de senescência em ambas as estações foram observadas em $\boldsymbol{P}$. notatum e A. affinis. A ocorrência de altas TEF observadas para as espécies com valores elevados de TSF pode ser considerada um evento esperado, pois a remobilização de nutrientes das folhas velhas para as folhas em elongação é um processo que acompanha a senescência foliar.

Paspalum notatum, no IL, apresentou competição contra sombreamento pelas demais espécies, já que, nesse tratamento, predominava o estrato superior, caracterizado por espécies de hábito de crescimento cespitoso. Essa resposta foi observada pelo aumento na TAF e redução no filocrono, na DVF e na DEF e ligeiro aumento na TEF. O resultado acima concorda com os autores JANSSON \& THOMAS (2008), que afirmam que a plasticidade do desenvolvimento vegetal demonstra que programas de desenvolvimento não são fixos, mas influenciados por fatores ambientais, a fim de tornar a planta bem adaptada ao novo ambiente.

\section{CONCLUSÃO}

Os intervalos de pastoreio baseados nas somas térmicas de 375 e 750 graus-dia não afetam significativamente a morfogênese dessas espécies. $\mathrm{O}$ efeito estacional na morfogênese das espécies é bem marcado, sendo primavera, estação de crescimento com maior aparecimento e elongação foliar, e verão, início do período reprodutivo, com alongamento dos entrenós e redução no crescimento foliar. As espécies do tipo funcional A apresentam maior aparecimento foliar na primavera e verão, sob pastoreio rotativo. Paspalum notatum é a espécie com maior potencial adaptativo às variações ambientais promovidas pelo pastejo, apresentando alterações consideráveis nas características morfogênicas. As características específicas dos tipos funcionais são reforçadas pelas respostas morfogênicas das plantas ao pastejo.

\section{REFERÊNCIAS}

BANDINELLI, D.G. et al. Variáveis morfogênicas de Andropogon lateralis Nees submetido a níveis de nitrogênio nas quatro estações do ano. Ciência Rural, v.33, n.1, p.71-76, 2003. Disponível em: <http://www.scielo.br/scielo.php?script=sci_arttext
\&pid=S0103-84782003000100011>. Acesso em: 20 fev. 2012. doi: $<\mathrm{http} / / / \mathrm{dx}$.doi.org/10.1590/S0103-84782003000100011>.

BEHLING, H.; PILLAR, V.D. Late quaternary vegetation, biodiversity and fire dynamics on the southern Brazilian highland and their implication for conservation and management of modern Araucaria forest and grassland ecosystems. Philosophical Transactions Royal Society B, v.362, p.243-251, 2007. Disponível em: <http://rstb.royalsocietypublishing.org/ content/362/1478/243.full.pdf + html $>$. Acesso em: 24 jan. 2012. doi: 10.1098/rstb.2006.1984.

BRISKE, D.D. Developmental morphology and physiology of grasses. In: HEITSHMIDT, R.K., STUTH, J.W. (Ed.). Grazing management: an ecological perspective. Portland, Oregon: Timber, 1991. p.85-108.

CARRÈRE, P. et al. Tissue turnover within grass-clover mixed swards grazed by sheep. Methodology for calculating growth, senescence and intake fluxes. Journal of Applied Ecology, v.34, p.333-348, 1997.

CRUZ, P. et al. Leaf traits as functional descriptors of the intensity of continuous grazing in native grasslands in the South of Brazil. Rangeland Ecology \& Management, v. 63, p.350-358, 2010.

INSTITUTO NACIONAL DE METEREOLOGIA (INMET). Divisão de Observação Meteorológica. Curso de atualização para observador meteorológico de superfície. Porto Alegre, 2004. 57p.

JANSSON, S.; THOMAS, H. Senescence: developmental program or timetable? New Phytologist, v.179, p.575-579, 2008. Disponível em: <http://onlinelibrary.wiley.com/doi/10.1111/ j.1469-8137.2008.02471.x/pdf>. Acesso em: 11 nov. 2011. doi: 10.1111/j.1469-8137.2008.02471.x.

MACHADO, J.M. Morfogênese de gramíneas nativas sob níveis de adubação nitrogenada. 2010. 77f. Dissertação (Mestrado em Zootecnia) - Curso de Pós-graduação em Zootecnia, Universidade Federal de Santa Maria, RS.

PILLAR, V.D. MULTIV, Multivariate exploratory analysis, randomization testing and bootstrap resampling. Porto Alegre: Departamento de Ecologia, UFRGS, 2004. Disponível em: $<$ http://ecoqua.ecologia.ufrgs.br/ 2004>. Acesso em: 12 set. 2011

QUADROS, F.L.F. et al. Morfogênese de Lolium multiflorum Lam. e Paspalum urvillei Steud sob níveis de adubação de fósforo e potássio. Ciência Rural, v.35, n.1, p.181-186 2005. Disponível em: <http:// www.scielo.br/pdf/cr/v35n1/a29v35n1.pdf>. Acesso em: 04 fev. 2012 doi: <http://dx.doi.org/10.1590/S0103-84782005000100029>.

QUADROS, F.L.F. et al. A abordagem funcional da ecologia campestre como instrumento de pesquisa e apropriação do conhecimento pelos produtores rurais. In: PILLAR, V.P. et al. Campos sulinos: conservação e uso sustentável da biodiversidade. Brasília-DF: Ministério do Meio Ambiente, 2009. p.206-213.

SANTOS, R.J. dos. Dinâmica do crescimento e produção de cinco gramíneas nativas do Sul do Brasil. 2005. $119 \mathrm{f}$. Dissertação (Mestrado em Zootecnia) - Curso de Pós-graduação em Zootecnia, Universidade Federal do Rio Grande do Sul, RS.

TRINDADE, J.P.P.; ROCHA, M.G. Rebrotamento de capim caninha (Andropogon lateralis Nees) sob efeito do fogo. 
Ciência Rural, v.31, n.6, p.1057-1061, 2001. Disponível em: $<$ http://www.scielo.br/pdf/cr/v31n6/a23v31n6.pdf $>$. Acesso em: 19 dez. 2011. doi: <http://dx.doi.org/10.1590/S0103$84782001000600023>$.

TRINDADE, J.P.P.; ROCHA, M.G. Rebrotamento de capim caninha (Andropogon lateralis Nees) sob o efeito de pastejo e fogo. Ciência Rural, v.32, n.1, p.141-146, 2002. Disponível em: <http://www.scielo.br/pdf/cr/v32n1/a24v32n1.pdf>. Acesso em: 14 mar. 2012. doi: <http://dx.doi.org/10.1590/S0103$84782002000100024>$.

VILELA, D. et al. Morfogênese e acúmulo de forragem em pastagem de Cynodon dactylon cv. 'coastcross' em diferentes estações de crescimento. Revista Brasileira de Zootecnia, v.34, n.6, p.1891-1896, 2005. Disponível em: <http://www.scielo.br/ pdf/rbz/v34n6/27241.pdf>. Acesso em: 25 mar. 2012. doi: <http:// dx.doi.org/10.1590/S1516-35982005000600012>. 